\title{
The association between HIV media campaigns and number of patients coming forward for HIV antibody testing
}

\author{
J D C Ross, G R Scott
}

\begin{abstract}
Aim-To assess the relationship between national and local media campaigns with respect to the number of patients requesting HIV antibody tests as a surrogate marker of the effectiveness of different campaign strategies.

Methods-Analysis by month of the numbers of HIV tests performed in the regional genitourinary (GUM) clinic for Lothian over a 5 year period and in the whole of Lothian Region, Scotland over a 3 year period. Changes in testing rates were monitored with respect to media campaigns over the same time period.

Results-Television based media campaigns produced the greatest increase in testing rates (average $46 \%$ increase over 2 months) compared with newspapers and poster campaigns (average 6\% increase over 2 months). Regional HIV testing rates correlated significantly with GUM clinic testing rates. No increase in positive HIV tests was seen following media campaigns.

Conclusions-Using HIV testing rates as a surrogate marker, television based media campaigns appear to be the most effective way of increasing awareness of HIV. The effect of media campaigns is short-lived indicating a need for constant reminder of the dangers of HIV infection. The increase in HIV testing occurs largely in the "worried well" with few additional HIV positive patients being identified.
\end{abstract}

(Genitourin Med 1993;69:193-195)

\section{Introduction}

In order to raise public awareness and knowledge about HIV disease a number of media campaigns have been launched over the past five years. These have been targeted at both a national (table 1) and a local level in the UK. The effectiveness of such campaigns is difficult to judge in precise terms but it is reasonable to postulate that increased awareness and concern regarding HIV may be reflected in increasing numbers of individuals coming forward for HIV testing. ${ }^{1}$

Changes in sexual behaviour secondary to media campaigns may be inferred by a reduction in other sexually transmitted diseases (STDs) which have the same risk factors as HIV but shorter incubation periods, such as gonorrhoea. In common with the rest of the UK there has been a marked decline in the
Table 1 Major HIVIAIDS Media Campaigns in Britain

December 1986 to February 1987

Don't die of ignorance

Television, press, posters, leaflets

February 1988

AIDS. You know the risk

Television, magazine adverts

Summer 1988

Holiday campaign

Posters in airports, ports and stations

December 1988 to March 1989

AIDS. You're as safe as you want to be

National press

Summer 1989

Holiday campaign

December 1989

World aids day

February 1990 to March 1990

Experts speak about HIV and AIDS

Television, national press

Summer 1990

Holiday campaign

Eastenders

December 1990

World AIDS Day

Summer 1991

Holiday campaign

November/December 1991

Death of Freddie Mercury/World AIDS Day

incidence of gonorrhoea in Scotland. ${ }^{2}$ The ability to assess the effectiveness of different modalities of media advertising in increasing public knowledge and changing sexual behaviour should enable resources to be concentrated on the most cost effective campaigns.

We have performed a retrospective analysis of the number of HIV tests performed in the Lothian region of Scotland over a five year period with particular attention to the association between HIV testing and media campaigns, both national (television based and non-television) and local.

\section{Methods}

Monthly totals of all HIV tests performed and numbers of positive results for the Lothian Region of Scotland between 1989 and 1991 were obtained from the Denominator Study which is co-ordinated by the Communicable Diseases (Scotland) Unit. ${ }^{3}$ These were compared with the number of tests performed over the same time period in the Department of Genitourinary Medicine (GUM), Edinburgh Royal Infirmary. A sub-analysis of HIV tests performed in the GUM Department between 1987 and 1991 was made with respect to sex of patient, sexual orientation and age. Comparisons were made between the number of HIV tests performed in Lothian and other regions in Scotland and also between all General Practitioners (GPs) 
Table 2 Changes in number of HIV tests performed in GUM outpatients 2 months prior and 2 months after media campaigns

\begin{tabular}{|c|c|c|c|c|}
\hline Campaign & $\begin{array}{l}\text { No. of tests } \\
2 \text { months prior }\end{array}$ & $\begin{array}{l}\text { No. of tests } 2 \text { months } \\
\text { duringlafter }\end{array}$ & $\begin{array}{l}\text { Number of increased } \\
\text { tests (over } 2 \text { months) }\end{array}$ & Percentage increase \\
\hline $\begin{array}{l}\text { Feb } 1988 \text { (TV) } \\
\text { Dec } 1989 / \text { Feb-Mar } 1990 \text { (TV) } \\
\text { Dec } 1990 \text { (TV) } \\
\text { Dec } 1991 \text { (TV) } \\
\text { Average for TV campaigns } \\
\text { June to Aug } 1988 \text { (non-TV) } \\
\text { Dec } 1988 \text { to Mar } 1989 \text { (non-TV) } \\
\text { June to Aug } 1989 \text { (non-TV) } \\
\text { June to Aug } 1990 \text { (non-TV) } \\
\text { June to Aug } 1991 \text { (non-TV) } \\
\text { Average for non-TV campaigns }\end{array}$ & $\begin{array}{r}80 \\
130 \\
182 \\
263 \\
106 \\
118 \\
93 \\
132 \\
229\end{array}$ & $\begin{array}{r}120 \\
148 \\
279 \\
439 \\
109 \\
95 \\
95 \\
115 \\
153 \\
243\end{array}$ & $\begin{array}{r}40 \\
18 \\
97 \\
176 \\
83 \\
3 \\
-23 \\
22 \\
21 \\
14 \\
8\end{array}$ & $\begin{array}{l}50 \\
14 \\
53 \\
67 \\
46 \% \\
4 \\
-19 \\
24 \\
16 \\
6 \\
6 \%\end{array}$ \\
\hline
\end{tabular}

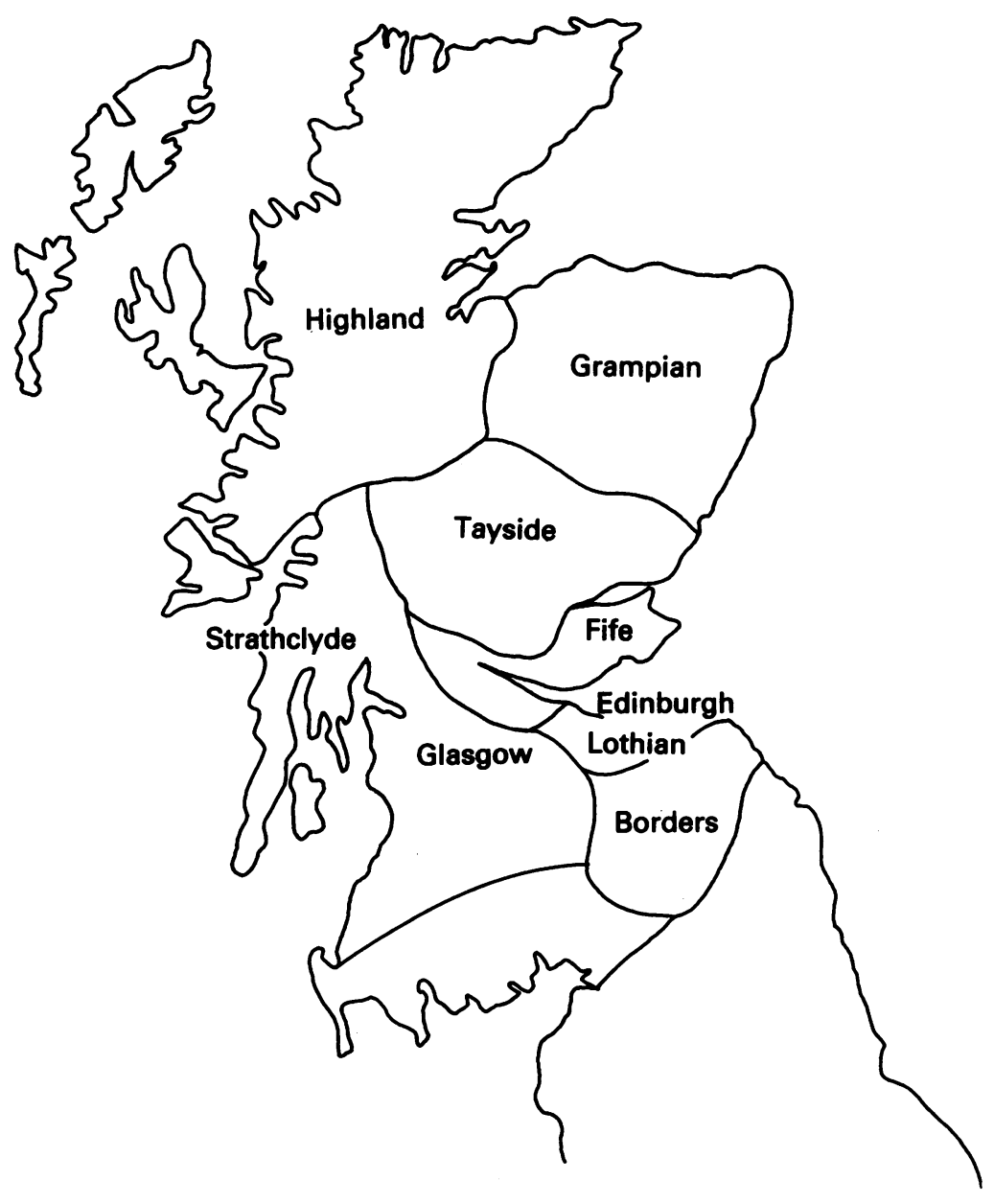

Figure 1 Map of Scottish regions.

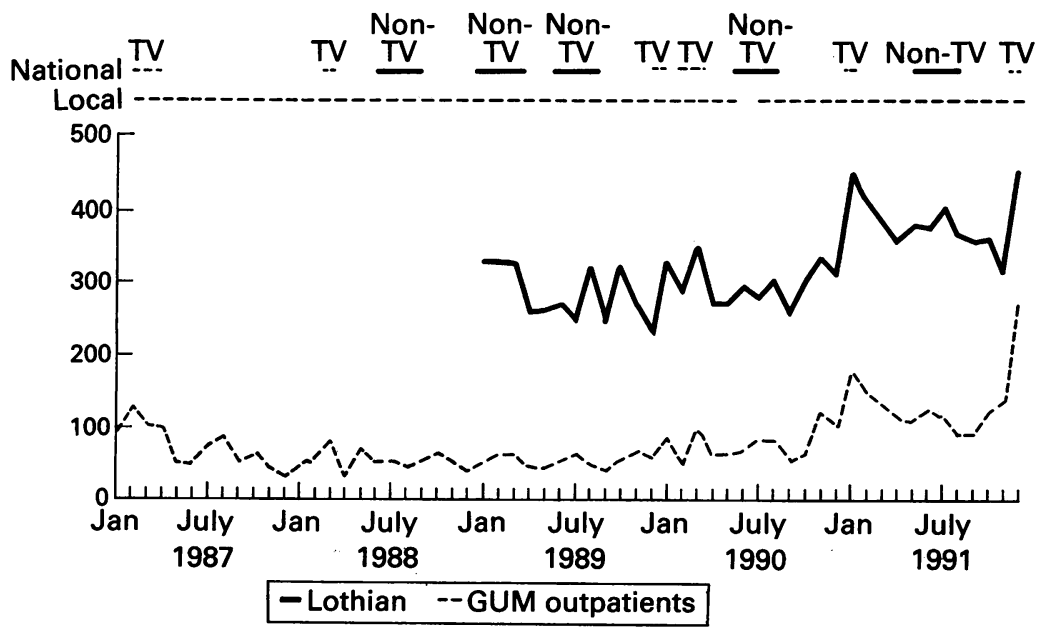

Figure 2 Monthly numbers of HIV antibody tests
Table 3 Correlations between HIV testing rates in different regions

\begin{tabular}{lll}
\hline & Lothian region & $p$ Value \\
\hline Greater Glasgow region & $\mathrm{r}=0.334$ & $\mathrm{p}=0.046$ \\
Grampian region & $\mathrm{r}=0.632$ & $\mathrm{p}<0.001$ \\
\hline
\end{tabular}

Table 4 Correlations between HIV testing in a GUM clinic and other centres

\begin{tabular}{lll}
\hline & $\begin{array}{l}\text { GU medicine } \\
\text { outpatients }\end{array}$ & p value \\
\hline General practitioners & $\mathrm{r}=0.538$ & $\mathrm{p}<0.001$ \\
"Other" outpatient departments & $\mathrm{r}=-0.046$ & $\mathrm{NS}$ \\
Lothian region & $\mathrm{r}=0.816$ & $\mathrm{p}<0.001$ \\
\hline
\end{tabular}

in Lothian, all "other" outpatient clinics in Lothian (including an HIV screening clinic on the outskirts of Edinburgh) and GUM Department outpatients. Testing rates 2 months prior and 2 months during/after each media campaign were compared. Local campaigns included leaflet distribution and advertising on local buses and ran almost continually through the study period. The geographical areas covered by the analysis are illustrated in fig 1 .

Statistical analysis was performed using the chi square test and $t$ test on Epi Info software package.

\section{Results}

Media campaigns and media events highlighting HIV running between 1987 and 1991 are shown in table 1 . The number of HIV tests performed in Lothian Region (between 1989 and 1991) and the GUM Department (between 1987 and 1991) are illustrated in fig 2 with the major media campaigns displayed graphically at the top of the figure. Changes in testing rates following television and nontelevision based campaigns are shown in table 2 and demonstrate a greater rise following television based campaigns $(p=0 \cdot 02)$. No correlation was demonstrated between the monthly number of positive and negative tests performed in the GUM Department outpatients (Figure 3, $r=0 \cdot 19$ ). The number of tests performed in the GUM Department did correlate significantly with the regional figures $(r=0.82, p<0.001)$. No significant correlation for positive HIV results between homosexual and heterosexual patients was found, but there was a correlation for negative HIV tests performed in homosexual and heterosexual patients $(r=0.6, p<0.001)$. 


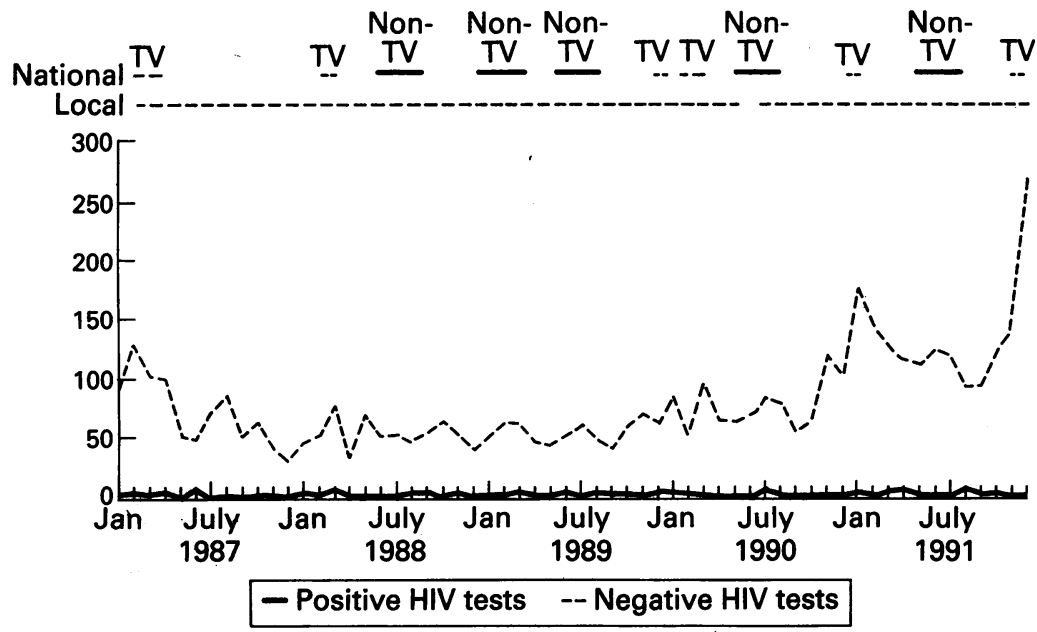

Figure 3 Negative and positive HIV antibody tests in GUM outpatients.

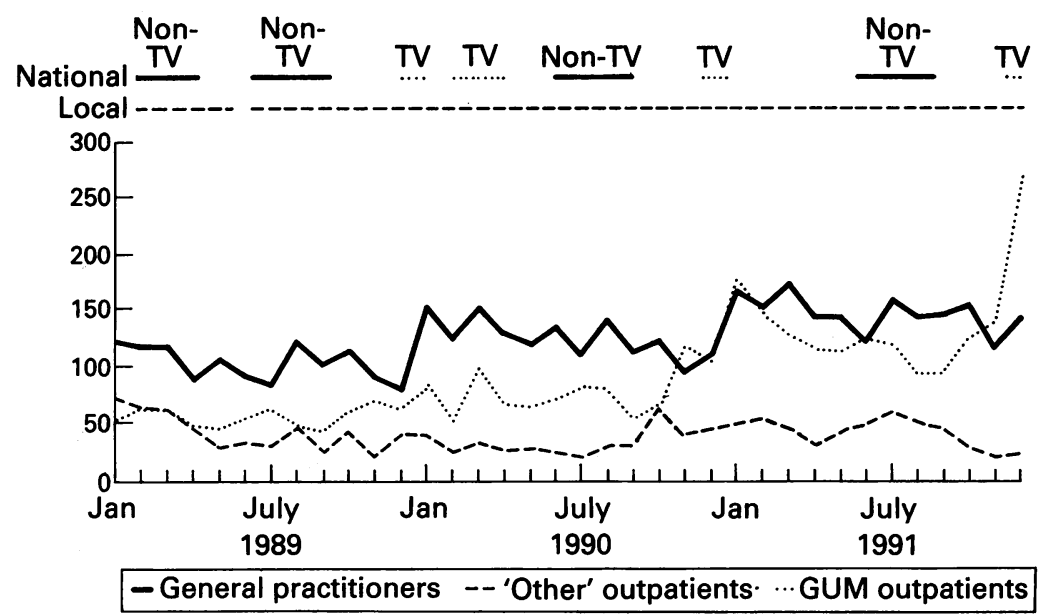

Figure 4 HIV antibody tests in Lothian by source

Regional differences in the monthly HIV testing figures were observed within Scotland. Grampian Region testing numbers correlated strongly with Lothian, while the Greater Glasgow Region did so to a lesser extent (table 3).

The monthly HIV testing rates for the GUM Department outpatients, General Practitioners and "other" outpatient departments in Lothian are shown in fig 4 and correlations between each group are in table 4 .

\section{Conclusions}

The number of HIV tests performed increased immediately following media campaigns directed against HIV. The increases were more marked when television was the medium used as compared with newspaper adverts and posters. Sherr ${ }^{4}$ showed no difference in the effect of poster and audiovisual presentation of information about the dangers of drug misuse in HIV. However, all participants in that study were exposed to the presentations and therefore comparisons with national media campaigns may not be valid. The two largest peaks for testing occurred in December 1990, when the television series Eastenders featured a heterosexual patient with HIV, ${ }^{5}$ and December 1991, when the rock singer Freddy Mercury died from AIDS. Both these events had extensive television coverage.

The effect of local campaigns is not possible to determine from this study but such campaigns may help to provide a baseline level of HIV knowledge.

Peaks following media campaigns were especially marked in a GUM clinic setting compared with "other" clinics and to a lesser extent for testing performed by GPs. This may reflect availability of tests at a city centre location in addition to the anonymity and confidentiality of a GUM clinic.

Media associated trends in HIV testing were less evident in the Greater Glasgow region of Scotland. This may reflect differing background knowledge and concern about the hazards of HIV infection. In Edinburgh (Lothian) over 700 patients have been diagnosed as HIV positive and it is estimated that 1 in 150 young people between the ages of 15 and 35 years are infected with HIV; therefore many individuals may know directly of an infected patient. In other cities in Scotland the infection rate is much lower and HIV may not generate the same concern even following media campaigns.

Although increased levels of testing may indicate greater public awareness of HIV this concern appears to be short-lived, with the number of patients coming forward for HIV testing dropping off rapidly to pre-campaign levels within 2-3 months. Also it does not appear that any additional HIV positive patients were identified as a result of more tests being performed. This suggests that the campaigns are not reaching those belonging to high risk groups, or at least is not encouraging them to come forward for testing.

Despite the cost of advertising on television this modality does appear to be the most effective way of raising public awareness if HIV testing rates are used as a surrogate marker of concern although it is not possible to directly link this to a subsequent change in sexual behaviour. Unfortunately there is no direct spin-off with regard to identifying more HIV positive patients in order that counselling and treatment may be offered although targeting the media campaigns towards high risk groups might help to identify more patients with HIV disease. Repeated reminders of the dangers of $\mathrm{HIV}$ infection are necessary to keep public awareness of HIV at a high level.

1 Beck EJ, et al. An update on HIV testing at a London Sexually Transmitted Diseases clinic: long term impact of the AIDS media campaign. Genitourin Med 1990;66:142-7.

2 Ross JDC, Scott G. Seasonal Variation in Gonorrhoea. Eur $\mathcal{F}$ Epidemiol 1992;8:252-5.

3 Goldberg DJ, et al. A system for surveillance of voluntary HIV testing: results of the first two years. AIDS 1992;6:495-500.

4 Sherr L. Fear Arousal and AIDS: do shock tactics work AIDS 1990;4:361-4.

5 AIDS and heterosexuality Lancet 1992;340:233.

6 Brettle RP. Implications of the Edinburgh AIDS epidemic for the United Kingdom. $尹$ Infect 1990;20:215-7. 